\title{
DA HAMARTIA COMO FALTA E A DIMENSÃO TRÁGICA DA VIDA NA PSICANÁLISE
}

Hugo Juliano Duarte Matias

\author{
Mestre em \\ Psicologia pela \\ Universidade \\ Federal do Rio \\ Grande do Norte, \\ e doutorando \\ em Psicologia \\ Clínica e Cultura \\ pelo Programa de \\ Pós-Graduação \\ em Psicologia \\ Clínica e Cultura, \\ da Universidade de \\ Brasília.
}

RESUMO: Trata-se da apresentação de elementos no pensamento freudiano que apontam para o modo como sua teoria não apenas aceita e comporta considerações acerca da tragédia, mas também localiza o psiquismo num sistema que depende da significação trágica da vida. Para tornar clara essa dimensão do pensamento freudiano, recorre-se a aspectos de seu trabalho com o texto de Sófocles - Édipo Rei. Propõe-se a construção de um diálogo entre Freud e Aristóteles. Extrai-se do conceito aristotélico de $\dot{\alpha} \mu \alpha \rho \tau i \alpha$, ou falta, o núcleo de uma articulação possível de sua concepção de tragédia e aquilo que diz respeito à dimensão trágica da vida no pensamento freudiano.

Palavras-chave: Culpa trágica; metapsicologia freudiana; hamartia.

ABSTRACT: From hamartia as fault and the tragic dimension of life in psychoanalysis. This paper presents elements in the Freudian thought to point how his theory not only accepts and contains considerations about tragedy, but also locates the psyche in a theoretical system that depends on the tragic meaning of life. Some aspects of Freud's work links with Sophocles' text — Oedipus Tyrannus - and are considered to clarify this dimension of the Freudian thought and lead to a construction of a dialogue between Freud Aristotle. The Aristotelian concept of $\dot{\alpha} \mu \alpha \rho \tau i \alpha$, fault, is the nucleus of a possible articulation of his conception of tragedy and what concerns the tragic dimension of life in the Freudian thought.

Keywords: Tragic guilt, Freudian methapsychology; hamartia. 
"Somos Edipo y de un eterno modo la larga e triple besta somos, todo lo que seremos y lo que hemos sido."

(Jorge Luis Borges)

Certamente, a literatura trágica obteve forte e variada influência sobre a cultura ocidental (KIMMELMAN, 1946), e de tal modo que a compreensão da dimensão trágica da vida, representada por essa forma da arte, é, também, um de seus efeitos. A suposição de que a tragédia concerne à vida humana da mesma maneira que à vida dos personagens trágicos é tão antiga quanto a própria arte trágica. Lesky (1957/1976) nos lembra o fato de que a palavra grega $\tau \rho \alpha \gamma \iota \varkappa o ́ \zeta$ foi usada de diversas formas ao longo do período clássico helênico, e, mais tarde, ora para significar certa grandiosidade relacionada a algum acontecimento, ora para apontar sua característica terrível. Em todo caso, ainda não se pode encontrar nisso os traços de uma cosmovisão trágica, nos mesmos termos daquela que conhecemos hoje. Permanece a questão sobre que processo teria conduzido a tal evolução.

Algo de muito curioso sobre esse tema é o fato de que as primeiras proposições para o sentido do trágico são do tempo em que a questão ainda não havia sido posta. Foram elas, justamente, que tiveram maior impacto sobre esse campo, e talvez tenham sido as mesmas a induzir o problema. Mcmahon (1929) apresenta as muito diversas fontes greco-romanas da crítica e filologia literárias sobre a tragédia, sua influência sobre a cultura, e situa a importância das obras aristotélicas Sobre os poetas e também a Poética. A Poética, em particular, tem produzido efeitos amplos sobre a crítica literária na medida em que o sistema que ela comporta fornece grande parte dos temas - descritos de forma esquemática por Gresseth (1958) - debatidos neste campo. Muito embora ele não tenha discutido o fenômeno trágico propriamente, a influência da Poética tornou-se mais forte sobre o ocidente a partir da Renascença, quando a ideia de "erro trágico" — de que se trata mais adiante - passou a exercer grande fascínio (RIGOLOT, 2004). Esse mesmo fascínio ainda afeta largamente a crítica literária e a crítica moderna de arte (KIMMELMAN, 1946).

Em todo caso, nela se poderiam encontrar as raízes da suposição de que a tragédia se refere não somente a algo abstrato, mas se constitui numa representação que remete à vida em sua concretude: "É que a tragédia não é a imitação dos homens, mas das ações e da vida" (1450a 17). E não se trata da representação da vida em seus acidentes, porque para ele, "a poesia expressa o universal" (Poética, 1451b 7-8). ${ }^{1}$ A vida é tomada pela poesia em seus traços essenciais, pelos quais se

\footnotetext{
${ }^{1}$ Tradução de A. M. VALENTE (2007). Lisboa: Fundação Calouste Gulbenkian. Para as citações diretas, menciono não a página desta edição, mas o passo e o verso, para facilitar sua busca em outras edições.
} 
reconhecem elementos de verossimilhança que remetem à experiência humana em sua potência, cuja representação localiza o agir humano em sequências que poderiam servir a qualquer pessoa para comparação com sua própria vida.

Se há algo de trágico na vida, se se quer encontrar em que ponto essa ligação é possível, decerto é preciso que se saiba o que é, propriamente, o trágico. Essa seria, com efeito, uma realização heroica. Não conto com a disposição ao compromisso com os seus embaraços e constrangimentos, e, segundo a proposta de Kitto (1939/1972), prefiro contentar-me com a ideia de que não há um modelo pelo qual se poderiam apreender todas as possíveis formas de representação trágica. Aliás, esse seria, segundo ele, um modo de encobrir a singularidade de cada dramaturgo, assim como a singularidade de cada uma de suas obras. O que tenho em mente é uma meta bem mais modesta, mais fácil, muito embora comporte algo de ousado. Trata-se da articulação entre uma das formas do suceder trágico com uma dimensão revelada por Freud acerca da experiência humana, em sua incidência sobre a constituição teórica no campo da psicanálise. Isto é, a dimensão trágica da vida que pode ser encontrada nas reflexões freudianas, construída com os recursos de um diálogo criado entre Freud e Aristóteles.

Obviamente, não se pode ignorar o fato de que Aristóteles está separado do momento histórico da produção dos mais importantes tragediógrafos gregos por pouco mais de um século, e que pretende apreender a sua literatura em esquemas racionais, adequados ao seu próprio sistema filosófico. O esforço em questão, portanto, é por discernir quais as operações que essa filosofia torna possível naquilo em que toca os apontamentos freudianos.

\section{A TRAGÉDIA NO CONTEXTO DE FREUD}

Tanto nas investigações de Aristóteles como nas de Freud, a tragédia de Sófocles - em especial, Édipo Rei — ocupa lugar de modelo. Em Aristóteles, modelo da arte quando imita a vida; em Freud, lhe serve para discernir a vida, sob o efeito das reverberações da arte. Mas no que concerne a Freud, é mais difícil propor uma relação próxima à tragédia mesma, pois não pode ser encontrada em sua obra uma reflexão particularizada sobre esse tema, muito embora tenha desenvolvido ponderações importantes que tocam o trágico para que isso pudesse favorecer o avanço de suas investigações psicanalíticas. Contudo, o contexto intelectual e artístico em cujo interior Freud desenvolveu o seu pensamento estava, indubitavelmente, submerso em reflexões sobre a tragédia, com Schelling, Hölderlin, Hegel, Goethe, Hebbel, Nietzsche, etc. Em fins do século XVIII, constituía-se uma passagem da reflexão sobre a poética do trágico - das considerações sobre fórmulas prescritivas acerca da poesia trágica — para uma 
filosofia do trágico como fenômeno. Tal preocupação atravessou todo o idealismo alemão, estendendo-se a diversos pensadores pós-idealistas, ao que parece, sempre sob uma forma de articulação dialética em diversos sistemas de oposição (necessidade e liberdade em Schelling, natureza e espírito em Hölderlin, por exemplo), tornando-se, por fim, num dos operadores de uma nova filosofia da história (SZONDI, 1964/2004).

Sabe-se que Goethe exerceu influência direta sobre Freud, com a sua reflexão sobre a tragédia e a sua própria produção trágica; e parece haver mesmo um parentesco entre seu pensamento acerca da tragédia — um "conflito, que não admite solução"2 - e o pensamento freudiano sobre o psiquismo. Além disso, as reflexões de filósofos, poetas e críticos, convergiam para uma ideia comum em torno da tragische Schuld, isto é, da culpa trágica. Isso assumiu um sentido metafísico em Hegel (1835/1964), por exemplo, que partilhava a ideia de que a tragédia se caracteriza por um conflito sem solução. Para ele, no enredo da tragédia, as diversas nuanças de uma única essência, que é o Espírito, se particularizam e, sob a contingência da realidade objetiva, que lhe dá a substância, entram em conflito e se combatem mutuamente. Fazem-no de modo irreconciliável, pois cada indivíduo que pretende impor a verdade de sua condição tem, nessa mesma verdade, o que o justifica. Ao mesmo tempo, negar a verdade do outro - que ele enfrenta - a qual procede da mesma essência, torna-o culpado. Esse seria o movimento necessário da história, de modo que a culpa trágica é também inescapável.

Sob o efeito de ideias como essa e de um interesse comum entre os românticos alemães, Hebbel tomou a culpa trágica como o ponto fulcral dessa forma de arte e de sua própria concepção do mundo, o que o levou à formulação de um "pantragismo" (SZONDI, 1964/2004). Tal culpa estaria relacionada a certo poder vital de que o homem se aparta no processo de sua individuação, um poder que ele desconhece. Ora, Freud era, certamente, leitor de Hebbel e se interessou, num dado momento, por traços de sua psicologia (FREUD, 1918/1996). Muito embora não se possa falar em Freud de uma Weltanschauung (palavra geralmente traduzida por 'cosmovisão'), sabemos bem que, em seu pensamento, o sentimento de culpa tem grande importância metapsicológica e é um dos grandes operadores do mal-estar de que padece o homem por sua relação com a cultura (FREUD, 1930/1996). Essa mesma culpa é intuída na tragédia de Édipo, um elemento que permanece obscuro, cujo paralelo com o homem comum corresponde ao fato de que também para ele a sua "origem lhe é desconhecida" (FREUD, 1917/1996, p.335). Por fim, em sua concepção, o "sentimento inconsciente de culpa" tem,

\footnotetext{
${ }^{2}$ Cf. ECKERMANN (1885/1950, p.211), no relato de uma conversa com Goethe em 28 de março de 1827, in Conversações com Goethe. Rio de Janeiro: Irmãos Pongetti Editores.
} 
justamente, um papel fundante no processo civilizatório (idem, 1913/1996), para cuja descrição Freud concebe um $\mu \tilde{v} \theta o \zeta$, o do assassinato do pai primevo,

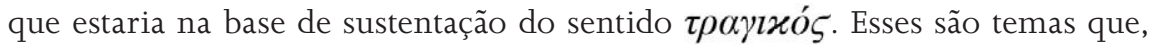
inequivocamente, aproximam o pensamento freudiano dessa tragische Schuld.

Em Totem e Tabu, Freud (1913/1996) faz remissão direta à tragische Schuld, que ele reconhece tanto como um elemento da arte trágica quanto como um fato da vida mental dos povos ao longo dos séculos. Freud se pergunta, referindo-se ao herói trágico, “qual era o significado de sua 'culpa trágica’?” (p.157-8). Querendo abreviar a sua resposta para isso, propõe que o herói mítico é o representante de uma figura primitiva que deve sofrer para expiar a culpa de seus irmãos, de toda a humanidade, do crime cometido contra o Pai, ou Deus. Segundo ele, esse é o mesmo herói que comparece no teatro grego, cuja função é expiar a culpa do Coro - representante do povo —, assim como a sua eficácia psicológica é a redenção do público de seu próprio sentimento inconsciente de culpa. Essa é a mesma argumentação que Freud assume em Moisés e o monotésmo (1939/1996), em que se refere à tragische Schuld quase que nos mesmos termos. Parece provável que ele estivesse tratando de um problema herdado do romantismo alemão, quando defende a sua argumentação dizendo que "aqui também está a verdadeira base para a 'culpa trágica' do herói do teatro, que, de outra maneira, é difícil de explicar" (p.101).

É neste ponto que ganha interesse a crítica de Vernant (1967/2005) ao uso que Freud faz da tragédia de Édipo, isto é, na psicologia histórica. Para ele, ficam elididos em Freud os planos centrais da tragédia no teatro grego relativamente ao seu contexto. Como exemplo, cita o fato de que o surgimento do "civismo" na transição entre os séculos VI e V a.C. impunha aos gregos uma reflexão — préfilosófica neste momento - acerca da responsabilidade no homem e do alcance de suas ações - principalmente em relação a um mundo de sentidos míticoreligiosos que esse agir desencadeia. Justo temas que, em Aristóteles, estariam resolvidos em sistemas rigorosamente filosóficos e, portanto, pós-trágicos.

Tal crítica tem suas razões e méritos em função de que, com efeito, não se pode harmonizar a interpretação freudiana e a interpretação historicizante dos helenistas sem prejuízo de ambas (como se pretendeu em certo momento). No entanto, o que se perde de vista nesta crítica é que da tragédia grega se herdou algo, que a ultrapassa, que transborda os limites concernidos pelos determinantes históricos de sua ascensão e declínio. E é isso que abre mais uma vereda para a reflexão sobre o trágico: além da história da tragédia grega, da poética trágica, da filosofia do trágico, uma consideração mais específica sobre a incidência e os efeitos da representação trágica.

Por isso, não podemos esquecer o tema da $\kappa \grave{\alpha} \theta \alpha \rho \sigma \iota \varsigma$, que concerne de maneira mais direta à reflexão sobre a tragédia, inclusive em termos aristotélicos. 
E é possível que, exatamente como um tema dos estudos aristotélicos, ele possa ter afetado o pensamento de Freud, pela provável influência de Jacob Bernays — tio de sua esposa, Martha — , que foi o responsável pela difusão de uma doutrina sobre a $\kappa \grave{\alpha} \theta \alpha \rho \sigma \iota \varsigma$ muito próxima daquilo que Freud viria a incorporar às suas proposições. Segundo esta doutrina, à $\kappa \grave{\alpha} \theta \alpha \rho \sigma \iota \varsigma$ corresponderia o alívio e purgação de emoções fortes (BERNAYS, 1857/2006). Esse conceito, que serviu à investigação freudiana no começo de suas descobertas, parece também reverberar em seu questionamento acerca do efeito que Édipo rei ainda provocava no público na virada para o século XX (FREUD, 1900/1996). Quando ele menciona que essa obra ainda consegue comover - e de um modo que as obras modernas já não o fazem - , explica o seu efeito pela ideia de que "deve haver algo que faz uma voz dentro de nós ficar pronta a reconhecer a força compulsiva do destino no Oedipus" (p.289). Com isso, faz ressoar em suas palavras a hipótese aristotélica de que a verdade poética é universal à medida que transcende a contingência e apreende a vida em seus possíveis.

Não se trata, meramente, de uma identificação ao herói trágico e ao seu sofrimento - como seria fácil pensar — , pois o efeito dessa peça diz respeito à verdade que a cena desvela, "mirror up to nature, to show virture her own feature, scorn her own image, and the very age and body of the time his form and pressure" ${ }^{3}$ Nas diversas ações e eventos que se sucedem em Édipo rei, encadeados pela necessidade dos arranjos construídos, em que as circunstâncias desviam as razões de cada personagem em equívocos sempre sobrepostos, o que Sófocles demonstra é o deslizamento de parte da realidade por debaixo de um véu, sob cuja enganosa estampa parece atuar uma compulsão. A verdade então se mostra também como co-incidência, pois “à medida que desvenda o passado, a culpa de Édipo, o poeta nos compele, ao mesmo tempo, a reconhecer nossa própria alma secreta" (FREUD, 1900/1996, p.289), apenas refletida nesse $\mu \tilde{v} \theta o \varsigma$ em que Édipo é representado como $\pi \alpha \rho \grave{\alpha} \delta \varepsilon \imath \gamma \mu \alpha$ (Édipo rei, $\left.{ }^{4} 1193\right)$, isto é, como exemplo, como modelo e como admoestação.

\section{A POÉTICA DO TRÁGICO EM ARISTÓTELES E SEU CONCEITO DE $\dot{\alpha} \mu \alpha \rho \tau i ́ \alpha$}

O efeito que Aristóteles supunha a essa operação, e que, segundo ele, deveria estar presente nas melhores tragédias, seria a produção e a $\kappa \grave{\alpha} \theta \alpha \rho \sigma ı \varsigma$, em cada

\footnotetext{
3 “... espelho para a natureza, para mostrar à virtude sua própria cara, ao escárnio sua própria efígie, e à exata idade e corpo de cada era a sua forma e força”. Hamlet, Shakespeare, Ato III, cena ii, vv. 1901-3. Tomo como referência a edição de W. G. CLARK \& W. A. WRIGHT (1864) The Works of William Shakespeare. Cambridge and London, UK: Macmillan and Co.

${ }^{4}$ Tradução de T. Vieira (2004). São Paulo: Perspectiva. Verso nas citações diretas segundo a edição de Sir R. JEBB (1887) Cambridge, UK: Cambridge University Press.
} 
pessoa da audiência, de paixões muito particulares: $\phi o ́ \beta o \varsigma$ e $c ̌ \lambda \varepsilon o \varsigma$. A primeira destas paixões, o terror ou medo, é produzida pela ruína de alguém a quem nos assemelhamos (Poética, 1453a 5-6). Aristóteles sugere, em sua Retórica, ${ }^{5}$ que quando o orador deseja inspirar temor em seus ouvintes ele deve "mostrar-lhes que pessoas como eles sofrem ou sofreram, por parte de quem não imaginavam, essas provações e circunstâncias que não esperavam” (Retórica, 1383a 12). Do mesmo modo, "temos compaixão [ou piedade] dos que nos são semelhantes (ónoíovৎ)” (Retórica, 1386a 25), se sobre eles sucede algum mal imerecido (Retórica, 1386b 6-7).

Deve ser considerado, ainda, outro elemento dessa semelhança que relaciona a pessoa do "herói trágico" ao público. Ora, o formato modelar da tragédia, ou o melhor tipo de tragédia, é aquele em que o caráter do herói trágico é mediano - isto não significa equilibrado. Esse caráter mediano está intimamente conectado à possibilidade de produção das paixões específicas que interessam à tragédia. Esse personagem não pode ser injusto, para que a sua queda não provoque benevolência ( $\phi i \lambda \hat{\alpha} v \theta \rho \omega \pi o v)$, e sua queda não pode ser completamente imerecida, para que não provoque repulsa ( $\mu \iota \alpha \rho o ́ v)$. Pelo recurso a um estudo do contexto moral estrito da transição do século V para o século IV a. C. em Atenas, Adkins (1966) demonstrou que o herói trágico tem de ser de

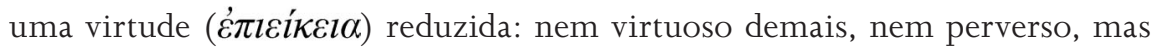
"entre"6 os dois, de modo a permitir que o homem médio ateniense, para quem o teatro era voltado, pudesse se reconhecer no personagem. A sua queda tem de ser imerecida, mas na medida exata para provocar terror e compaixão — queda desde certa altura (LESKY, 1957/1976). Porque o mais importante com relação

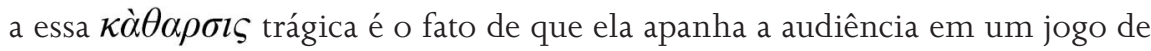
perto-longe, presente-ausente, na encenação da condição humana. Trata-se, para Aristóteles, da "aproximação do temível” (Retórica, 1382a 31-2), ${ }^{7}$ e também "os infortúnios que parecem próximos são dignos de compaixão" (Retórica, 1386a 29-30 [8]). ${ }^{8}$ Constitui-se, assim, o paradoxo pelo qual, ao mesmo tempo, a tragédia não nos concerne e nos despedaça (LEAR, 1988, p.324), re-velando a dimensão trágica da vida na artificialidade dessas paixões construídas por simpatia ( $\sigma \nu \mu \pi \alpha ́ \alpha \chi o v \tau \varepsilon \varsigma)$.

Ora, terror e compaixão estão intrinsecamente ligados a $\pi \varepsilon \rho l \pi \varepsilon ́ t \varepsilon l \alpha l$ e

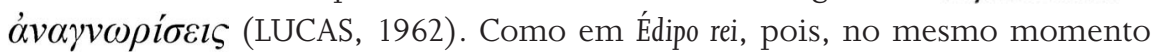
que há o reconhecimento (’́v $\alpha \gamma v \omega \rho i ́ \sigma \varepsilon ı \varsigma)$ do crime de Édipo, a sua sorte sofre o revés $(\pi \varepsilon \rho \imath \pi \varepsilon ́ \tau \varepsilon l \alpha l)$, são exatamente essas duas partes de seu enredo — prin-

\footnotetext{
${ }^{5}$ Tradução de I. B. FONSECA (2000) A Retórica das Paixões. São Paulo: Martins Fontes.

${ }^{6} \mu \varepsilon \tau \alpha \xi \dot{v}$, Poética, $1453 a 7$.

${ }^{7} \phi о \beta \varepsilon \rho o v \hat{\pi} \lambda \eta \sigma l \alpha \sigma \mu o ́ s$.

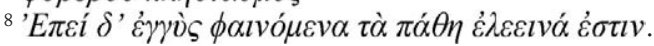


cipalmente quando ocorrem ao mesmo tempo - que, nas palavras de Aristóteles, “capturam a alma” (Poética, 1450a 34 [9]) 9 do público, quando cada um na audiência, por assim dizer, reconhece também a sua própria alma secreta.

Assim chegamos ao ponto mais importante do desenho concebido por Aristóteles para a tragédia modelo. Se é preciso que haja uma queda, se essa queda deve, ao mesmo tempo, acometer alguém justo, sendo imerecida, mas sem causar repulsa, sentimento de satisfação, qual deveria ser o seu dispositivo? Há uma transformação $(\mu \varepsilon \tau \alpha \beta o \lambda \eta ́)$ cuja direção é da fortuna ( $\varepsilon v \dot{\tau} v \chi i ́ \alpha)$ para o infortúnio ( $\delta v \sigma \tau v \chi i \alpha)$, e o que a opera em seu núcleo - portanto, no núcleo da tragédia - é o que Aristóteles chama de $\dot{\alpha} \mu \alpha \rho \tau i \alpha$. Esse conceito causou uma longa série de mal-entendidos durante a história da exegese da Poética. Aqui, tomo como referência a discussão desse termo feita por Bremer. Depois de estudo filológico detalhado, ele define ‘ $\mu \alpha \rho \tau i \alpha$ como “"erro trágico', isto é, uma ação equivocada cometida sob ignorância de sua natureza, efeito, etc., que é o ponto inicial de uma cadeia de eventos causalmente conectados, culminando com o desastre" (1969, p.63). Em um de seus argumentos, Bremer (1969) situa esse conceito na teoria aristotélica da ação, apresentada em dois momentos em sua Ética a Nicômaco. Interessa-nos o segundo.

A $\dot{\alpha} \mu \alpha \rho \tau i \alpha$ do capítulo 13 da Poética é uma ação realizada sob ignorância de qualquer de seus elementos (circunstâncias, objeto, instrumento, efeitos e, inclusive, uma ignorância relativa ao próprio agente da ação). As faltas cometidas sob ignorância são $\dot{\alpha} \tau v \chi \eta \mu \alpha$ ou $\dot{\alpha} \mu \alpha \rho \tau \eta \mu \alpha$, as quais se opõem a $\dot{\alpha} \delta \imath \kappa \eta \mu \alpha$, categoria que compreende as faltas causadas por paixões incapazes de autorrefreamento ( $\alpha \kappa \rho \alpha \sigma i ́ \alpha)$ e por maldade ( $\kappa \alpha \kappa i \alpha v)$. O prejuízo causado por estas

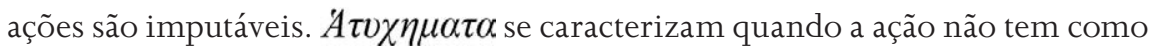
sua causa o próprio agente, mas algo que escapa ao seu conhecimento ou expectativa, sendo-lhe estranho - algo que também age sobre ele, e é nisso que está a injúria que produz o dano. Por isso, sequer o dano pode ser atribuído ao agente. A $A \alpha \rho \tau \eta \mu \alpha \tau \alpha$ se caracterizam ainda quando a ação é reconhecida pela comunidade como injuriosa, cuja causa repousa sobre o agente, a despeito de sua ignorância sobre esta. Deste modo, o dano lhe é atribuído, mas não o dolo (equivalente ao crime culposo). Assim, por obra de sua $\dot{\alpha} \mu \alpha \rho \tau i \alpha$, que transforma $(\mu \varepsilon \tau \alpha \beta o \lambda \eta ́)$ sua sorte, o herói se conduz à ruína sem, no entanto, merecê-la. O que é tratado como uma distinção entre causa moral e não moral da ação é mal entendida como falta moral séria ou trivial. A $\mu \alpha \rho \tau i \alpha$ é "ato injurioso, cometido porque o agente era inconsciente de alguma circunstância vital" (BREMER, 1969, p.20).

\footnotetext{
${ }^{9} \psi v \chi \alpha \gamma \omega \gamma \varepsilon \hat{\imath}$.
} 
A $\dot{\alpha} \mu \alpha \rho \tau i ́ \alpha$, esta falta ${ }^{10}$ que constitui o evento central do metabolismo trágico, de modo algum pode ser associada, em termos aristotélicos, a qualquer falha moral, e tem como a sua principal característica a ignorância que a ela está atrelada. É justamente por causa da presença marcante desta dimensão da vida humana em Édipo rei que esta peça constitui o modelo mais interessante para a representação do mito trágico. O engano acerca da natureza desta falta, em interpretações moralizantes, tem velado aquilo em que de fato consiste o impacto desta peça.

“Certamente Édipo Rei é uma peça sobre a cegueira do homem e a insegurança desesperada da condição humana: num certo sentido, todo homem deve tatear na escuridão como Édipo fez, sem saber quem ele é e o que tem de sofrer; nós todos vivemos num mundo de aparência que oculta de nós a terrível realidade do não saber." (DODDS, 1988, p.187)

\section{A INTERPRETAÇÃO FREUDIANA E O CONCEITO DE HAMARTIA}

A profunda ignorância e, em certa medida, algo de uma impossibilidade de saber, são elementos indispensáveis à leitura dessa peça, sendo também imprescindíveis à compreensão daquilo que pertence intimamente ao psiquismo. Freud não os desconsiderou no uso modelar que fez do texto de Sófocles, pois, para ele, “a ignorância de Édipo constitui representação legítima do estado inconsciente em que, para os adultos, toda a experiência caiu” (FREUD, 1938/1996, p.205). Mas também não se trata de uma simples ignorância, um desconhecimento qualquer dos fatos e das circunstâncias que, na forma de má sorte, opera a ruína de Édipo $\mathrm{p}$ - e esse é mais um dos tesouros encontrados por Freud na $\mu i ́ \mu \eta \sigma ı \varsigma$ trágica. Ele vê nessa tragédia “o impacto de uma advertência a nós mesmos e a nosso orgulho, nós que, desde nossa infância, tornamo-nos tão sábios e tão poderosos ante nossos próprios olhos. Como Édipo, vivemos na ignorância” (FREUD, 1900/1996, p.289). Essa ignorância não é outra senão autoengano. Ela constitui, sob os modos de uma presunção, o que Vernant (1964/2004) propõe como a v̋ $\rho ı \varsigma$ tirânica de Édipo, o seu excesso, a saber, a sua confiança exacerbada em seu próprio julgamento $(\gamma v \omega ́ \mu \eta)$.

Podemos pensar em duas causas para a queda de Édipo: imediata e remota. A segunda diz respeito aos crimes cometidos por ele: parricídio e incesto. Facilmente identificamos este fato à única ligação da peça com o destino humano

\footnotetext{
${ }^{10}$ Muito embora o uso cada vez mais comum para a tradução de $\dot{\alpha} \mu \alpha \rho \boldsymbol{t}^{\prime} \alpha$ seja erro, ou "erro trágico", opto pela palavra "falta" por dois motivos: (a) certa ambiguidade que ela comporta, a qual parece interessante para sustentar o sentido complexo que o conceito assume nessa discussão; (b) por suas possíveis ressonâncias no contexto da apreciação psicanalítica.
} 
- numa leitura apressada de Freud. No entanto, ele nos mostra que é trágico também o fato de ignorarmos, principalmente, a possibilidade de que o nosso destino nos alcance, ou que o alcancemos nós no percurso de nosso próprio desejo. E isso faz parte da queda de Édipo, pois ele ignorou a possibilidade de que o seu caminho se cruzasse com os caminhos de seus próprios pais. Quanto a isso, Sófocles é impressionante em ironia: é num cruzamento de três caminhos que Édipo assassina o próprio pai, e de onde parte para o encontro de sua mãe; e é justo quando essa "tripla intersecção das estradas” (Édipo rei, 716) ${ }^{11}$ é mencionada por Jocasta como o local em que ocorreu o assassinato de Laio que, pela primeira vez, a alma de Édipo se agita (Édipo rei, 727). Esta encruzilhada fará parte do lamento de Édipo (Édipo rei, 1398-1408).

Não parece ser sem propósito que esta fala de Jocasta esteja no contexto de sua intenção de desacreditar as palavras de Tirésias. Aí também se cruzam a causa imediata e a causa remota do infortúnio de Édipo. Se esta diz respeito aos seus crimes, aquela consiste em sua busca pela verdade, ignorando o fato de que essa mesma verdade o concerne. Ricoeur (1969) propõe que o conflito que subjaz a essa tragédia não é o enfrentamento entre homem e deuses, destino, ou sociedade, mas entre o homem e a verdade que lhe toca. Édipo presume não ser concernido pela verdade, e é isso que impele a sua busca por ela.

A segurança com que Édipo determina sobre si mesmo o encargo de trazer a verdade à luz se sustenta sobre a ilusão de poder se furtar a essas encruzilhadas, a suposição de que a sua busca por saber não lhe implicaria com as suas consequências. É muito comum encontrarmos, sob a forma de tragédias como essa, uma operação muito própria do trágico, “a queda de um mundo ilusório de segurança e felicidade para o abismo da desgraça ineludível” (LESKY, 1957/1976, p.26). Assim, Édipo deixou-se acreditar que estava seguro, do mesmo modo que Macbeth deixou-se repousar sobre a própria presunção, “and now a wood comes toward Dunsinane". ${ }^{12}$

\section{A INTERPRETAÇÃO LACANIANA}

Em sua interpretação de Freud, assim como em seu próprio trabalho com a psicanálise, também Lacan (1959-60/1997) apresenta a tragédia no primeiro plano da experiência propriamente analítica, muito mais em seu caráter originário que por sua ligação ao complexo de Édipo. Tal origem seria a ideia de $\kappa \grave{\alpha} \theta \alpha \rho \sigma \iota \varsigma$ e a atração que exerce é onde se deve procurar o verdadeiro sentido da tragédia (p.296). Neste seminário, ele discute duas formas pelas quais se pode articular

\footnotetext{
${ }^{11} \tau \rho l \pi \lambda \alpha l \hat{\zeta} \dot{\alpha} \mu \alpha \breve{\zeta ̆} \imath \sigma o \hat{\zeta}$.

12 "e agora o bosque vem a Dusinane". Macbeth, Ato V, cena v, vv. 2405-6. Edição de W. G. CLARK \& W. A. WRIGHT (1864).
} 
a dimensão da falta ao trabalho freudiano: como crime e infração (faute) — que associa ao assassinato do pai ao processo de surgimento da cultura - e como lacuna, ausência e erro (manque), que associa à Coisa freudiana (das Ding) e ao processo de assunção do psiquismo sob as ordenações do desejo.

Esses dois sentidos da falta parecem convergir em sua abordagem do problema da relação entre Lei e desejo, quando toma a $\dot{\alpha} \mu \alpha \rho \tau i ́ \alpha$, na epístola de São Paulo aos Romanos, no capítulo 7, em relação à Coisa. Com relação à Coisa da satisfação perdida, a $\dot{\alpha} \mu \alpha \rho \tau i \alpha$ - o pecado, que é como consta em São Paulo — apareceria como resto de gozo, como a dívida constituída em um tempo que é mítico, que a Lei cria e revela. Pois o gozo apenas é contabilizado como tal, isto é, como suposição, sob a forma da transgressão e depende, por sua vez, de outra forma que lhe dá forma, que é a Lei (LACAN, 1959-60/1997, p.216-7). Essa transgressão foi formulada por Freud nos termos do assassinato do pai, e é por isso que encontra na tragédia de Édipo uma representação tão vívida.

Em todo caso, Lacan tomou a Antígona ${ }^{13}$ como fulcro de uma pesquisa sobre a estrutura da ética trágica, sob a hipótese de sua homologia à ética da psicanálise. Nessa peça, ele isolou algumas funções que operam no interior dessa ética. A figura de Creonte ilustra uma delas, a de um "querer o bem" que implica o

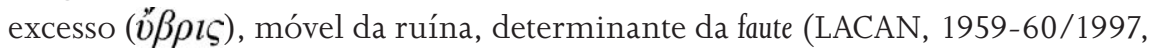
p.313). Mais uma vez, trata-se de $\dot{\alpha} \mu \alpha \rho \tau i ́ \alpha$, agora em sua formulação aristotélica — tomada no encontro com sua "ciência da felicidade" —, que ele apreende num sentido pouco claro, em função, talvez, da longa tradição de mal-entendidos a que já aludimos, traduzindo-a por "erro de julgamento", embora admita que esse sentido não seja completo. Para ele, então, isso estaria num segundo plano com relação àquilo que concerne à essência da ética trágica, tal como a personagem Antígona a revela.

O plano principal seria o da ǒxt , em cujo âmbito limítrofe Antígona parece

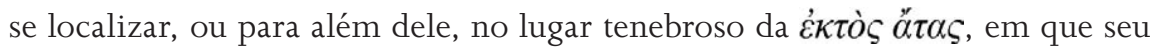
desejo se apresenta como tal, singularizado e sem constrangimentos outros, diante do qual se projeta um bem que não é de todos, que não se harmoniza ao $\kappa \dot{\rho} v v \mu \alpha$, à proclamação de Creonte. A transposição desse limite — o limite propriamente humano - lança Antígona para fora da vida, num lugar que também é "entre", e a reveste de uma atratividade arranjada ainda pelo movimento de perto-longe, pelo que organiza a sua beleza sublime. Com isso, Lacan rejeita a proposta aristotélica de que o metabolismo da tragédia seja sempre a $\dot{\alpha} \mu \alpha \tau^{\prime} i \alpha$. Esta seria a besteira que leva Creonte à ruína, mas a perda propriamente trágica concerne à indestrutibilidade do desejo que impele para além da ă $t \eta$.

\footnotetext{
13 Tradução de M. G. KURY (2008) A trilogia tebana. Rio de Janeiro: Jorge Zahar Ed. Verso das citações diretas segundo edição de Sir R. JEBB (1891).
} 
Mesmo assim, a hipótese da utilidade de se pensar a $\dot{\alpha} \mu \alpha \rho \tau i ́ \alpha$ como reveladora de pelo menos um dos aspectos da ética da análise, ou da dimensão trágica da vida, pode ser recuperada ainda a partir de Lacan (1959-60/1997), se considerarmos dois fatores: a) o equívoco corrente acerca do sentido do termo $\dot{\alpha} \mu \alpha \rho \tau i \alpha$ em Aristóteles; e b) o fato de que o seminário sobre $A$ ética da psicanálise foi desenvolvido dentro das fronteiras do campo do desejo. A retomada deste tema, sob a referência do seminário do Avesso da psicanálise (LACAN, 1969-70/1992), a saber, uma retomada desde o campo do gozo, permite a reabilitação do conceito de $\dot{\alpha} \mu \alpha \rho t i \alpha$. Antes, voltemos à Antígona.

Tomemos a $\dot{\alpha} \mu \alpha \rho$ tí em sua relação à Coisa e à Lei, tal como Lacan já havia apresentado, e pensemos nela como um resto de gozo condensado como transgressão, excesso, $v \beta \rho \imath \iota$. Antes de tomar qualquer direção, Antígona pensa em voltar onde jaz Édipo, movida tão-somente por seu desejo (Édipo em Colono, $1723)^{14}$ e, ainda no início da peça que leva seu nome, declara não haver ó̆t que, por ser herdeira de Édipo, ela já não conheça, sendo isto mesmo que a liga ao destino dessa família. "Desventurada filha de desventurado pai — de Édipo! Que isto significa?” (Antígona, 380-2) interroga o Coro, e dele mesmo encontramos alguns sentidos, pois a $\mu \varepsilon \rho i ́ \mu v \alpha$ a que alude Lacan é a memória dos pecados cometidos pelo pai de Antígona no tálamo materno, manifesto em três gerações de Labdácidas, os quais ela deve expiar (Antígona, 856-65). Assim, essa ớ $\tau \eta$ que localiza Antígona, como Lacan mesmo o nota, estaria ligada "a um começo e a uma cadeia, a da desgraça da família dos Labdácidas” (1959-60/1997, p.319). Esta seria uma forma de ler os versos que oferecem o material sobre o qual Lacan trabalha:

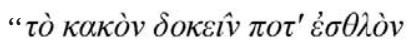

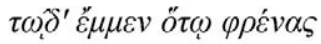

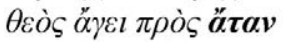

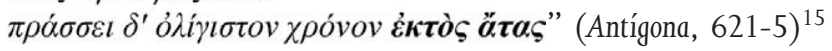

Do mesmo modo que em Creonte estão associadas $\ddot{\alpha} \tau \eta$ e $\dot{\alpha} \mu \alpha \rho \tau i \alpha:$ ov̉

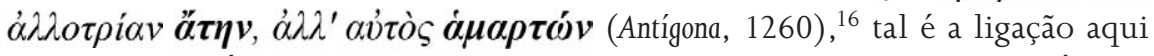
sugerida entre Édipo e Antígona: ela está diretamente ligada ao gozo em Édipo, e se apreende como resultado, produto e resto disso. É desse modo exato que sua $\ddot{\alpha} \tau \eta$ se conecta à $\dot{\alpha} \mu \alpha \rho \tau i \alpha$ de Édipo, porque aquela lhe advém do Outro, sendo

\footnotetext{
14 Tradução de M. G. KURY (2008). Verso nas citações diretas segundo a edição de Sir R. JEBB (1889).

15 “... cedo ou tarde, o mal parecerá um bem àquele que os deuses resolveram desgraçar. E são momentos poucos e fugazes os que ele vive livre da desdita”.

16 “... não de alheia insânia, mas de erros que ele mesmo cometeu”.
} 
por ela unida ao leito incestuoso de seu pai e sua mãe: $\dot{\alpha} \mu \alpha \rho \tau i ́ \alpha$ (Édipo) $\leftarrow \grave{\alpha} \tau \eta$ (Antígona). Com relação à Antígona, a faute de seu pai, sua $\dot{\alpha} \mu \alpha \rho \tau i \alpha$, é a parcela de gozo, ou a suposição de gozo possível (mais-de-gozar) que ela herda, de um pai imaginarizado, se evocarmos a incidência do campo do gozo, melhor delineada no seminário do Avesso (LACAN, 1969-70/1992), sobre essa leitura de Antígona. Esse pai pecador! O pecado do pai é contabilizado como operador da maldição, da impossibilidade de seu próprio gozo - Antígona é barrada em seu acesso às

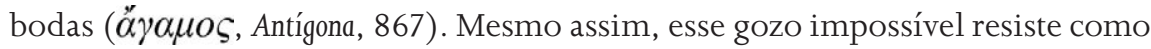
enigma, sendo o que determina a ação e a justificativa de Antígona para fora das leis escritas $(\delta \imath \kappa \eta)$ - portanto, fora da $\dot{\alpha} \delta \imath \kappa \eta \mu \alpha$. Ora, o que Antígona parece buscar, desde Édipo em Colono (1727) — não obstante a interdição feita quanto a este saber sobre o pai, pois ela não deveria conhecer o lugar de seu sepultamento (Édipo em Colono, 1761-5) — , acaba conseguindo: visitar a morada profunda ${ }^{17}$ de seu pai morto: objeto $\alpha(\rightarrow \dot{\alpha} \mu \alpha \rho \tau i \alpha)$.

Do mesmo modo, a tragédia do próprio Édipo gira em torno de um saber que lhe resiste e que o leva à ruína. Lacan (1969-70/1992) apresenta o mito de Édipo, tal como apreendido por Freud, em sua dimensão trágica, apontando para o fato de que o que este revela é a chave do gozo. Não é bem do pai morto que se trata, mas do pai assassinado, pois é essa a condição de gozo (p.113). No entanto, esse gozo não se torna possível pelo assassinato puro e simples, pois o acesso a ele passa por um teste no campo do saber: Édipo responde ao enigma da esfinge, elidindo a verdade que dividia o povo de Tebas, e o preço disso é a sua ruína, porque a verdade retorna em sua estrutura de semi-dizer e o captura mais uma vez. Assim, como ele não se deu conta de que a resposta do oráculo era de um saber não-todo (não se lhe disse quem eram os seus pais), presumindo que nada ali permanecia oculto, pôs-se em fuga de seu próprio destino; em consequência, acabou por encontrá-lo. Do mesmo modo, a resposta dada por ele à esfinge lhe revelou a glória de seu destino como rei e lhe ocultou a monstruosidade que essa condição implicava.

Como aponta Lacan (1969-70/1992), o saber é meio de gozo, pois se trata da repetição em busca da experiência de satisfação que não pode ser recuperada, uma repetição que, portanto, produz diferença $\left(\mathrm{s}_{1} \rightarrow \frac{\mathrm{S}_{2}}{\alpha}\right)$. Desse modo, o gozo implicado no saber é aquele que se perde (falta/manque), pois o produto do trabalho do saber é entropia. No campo do sentido, em sua relação com o saber, esse produto comparece como verdade, mas a verdade da castração. E é isso, no final das contas, que vem sendo escamoteado na relação de Édipo ao saber. No final do processo investigativo de Édipo, a intervenção do pai assassinado produz justamente a castração. Aqui, a dimensão mítica ultrapassa a dimensão trágica de

${ }^{17} \tau \grave{\alpha} v \chi \theta o ́ v ı o v$, Édipo em Colono, 1725. 
toda essa articulação, pois o pai assassinado, morto, se revela, ao mesmo tempo, como operador estrutural da castração e equivalente ao gozo, como perdido trata-se da $\dot{\alpha} \mu \alpha \rho \tau i ́ \alpha$ de Édipo. Não saber é não saber do gozo como impossível; assim, certa medida de renúncia ao saber corresponde à renúncia pulsional, pois a renúncia é o modo pelo qual o impossível se inscreve pela operação de um saber que não se sabe. O núcleo desse saber que não se sabe, como aqui se propõe, é a $\dot{\alpha} \mu \alpha \rho \tau i \alpha$.

\section{CONSIDERAÇÕES FINAIS}

É preciso notar que Freud reconheceu a relação de Édipo com o saber na forma de uma presunção, e com essa revelação produziu a possibilidade de um desvio. Ele apresentou a sua descoberta de um complexo inconsciente cujo conteúdo é semelhante àquele da trama da tragédia grega, e o modo como articulou essa descoberta, descrito em uma carta a Fliess (FREUD, 1897/1996), revela a sua crença de ser ele mesmo concernido por essa verdade, antes ignorada, mas que produz determinações sobre o seu psiquismo. A possibilidade de desvio em que consiste a própria psicanálise depende da incidência dessa dimensão trágica da vida sobre o pensamento freudiano. Uma falta, uma impossibilidade, $\dot{\alpha} \mu \alpha \rho \tau i \alpha$ — como se propõe — , nos leva à mesma encruzilhada de Édipo. A psicanálise é um procedimento de investigação, um método, por assim dizer. Ela guarda, como o próprio Freud reconheceu, alguma semelhança com os expedientes utilizados na composição do texto sofocliano (FREUD, 1917/1996, p.334) para re-velar a dimensão gozosa da verdade.

Trata-se de uma busca pela mesma verdade, ou por uma nova forma de se fazer concernido por essa verdade, na qual se enfrentam barreiras semelhantes àquelas que Édipo enfrentou. Mas uma diferença fundamental consiste no fato de que a análise começa justamente no momento que se chega à suspeita da verdade. Lacan (1960-70/1992) afirma que, em relação a essas formulações, o trabalho que compete ao analista é fazer "funcionar seu saber em termos de verdade" (p.50), ou seja, lá onde se poderia contabilizar o gozo, como gozo do Outro, a palavra, o ato do analista, se faz contar como verdade não-toda. É aqui que Lacan situa a função do Édipo em psicanálise, a de ser esse saber em que se sustenta o analista como semblante, com pretensão de verdade, isto é, $\frac{\alpha}{S_{2}} \rightarrow \frac{S}{S_{1}} \equiv \frac{\alpha}{\mathrm{OE}} \rightarrow \frac{S}{S_{1}}$.

O objetivo dessa busca, com isso, passa a ser uma mudança de posição em relação à verdade, algo também semelhante ao modo como se encerra essa tragédia. Não se trata de autopunição, certamente, mas relaciona-se ao segundo aspecto, levantado por Dodds (1988), com respeito àquilo de que Édipo rei nos 
fala: a força de Édipo em perseguir a verdade, a despeito do custo de sua própria vida, e também a grandeza de tomar sobre si a responsabilidade por todos os seus atos. Édipo diz: "Meu infortúnio é tanto que somente eu, e mais ninguém, será capaz de suportá-lo nesta vida!”. A formulação freudiana seria “wo es war, soll ich warden"! 18

Recebido em 3/8/2009. Aprovado em 15/4/2010.

\section{REFERÊNCIAS}

ADKINS, A.W.H. (1966) "Aristotle and the best kind of tragedy", in The Classical Quarterly, v.16, n.1. Cambridge, UK: Cambridge University Press, p.78-102.

BERNAYS, J. (1857/2006) "Aristotle on the effect of tragedy", in A. LAIRD (Ed.), Ancient Literary criticism, p.158-175. Oxford, USA: Oxford University Press.

BREMER, J.M. (1969) Hamartia. Amsterdam: Adolf M. Hakkert.

DODDS, E.R. (1988) "On misunderstanding the Oedipus Rex", in SEGAL, E. (Ed.), Oxford readings in Greek Tragedy. Oxford: Oxford University Press.

FREUD, S. (1996) Obras psicológicas completas de Sigmund Freud: edição standard brasileira. Rio de Janeiro: Imago.

(1897) “Carta 71", v.I, p.314-317.

(1900) “A interpretação dos sonhos”, v.IV, p.13-363.

(1913) “Totem e tabu”, v. XIII, p.21-162.

(1917) "Conferência XXI — O desenvolvimento da libido e as organizações sexuais", v.XVI, p.325-342.

(1918) “O tabu da virgindade”, v.XI, p.197-216.

(1930) "O mal-estar na civilização”, v.XXI, p.65-148.

(1933) "Conferencia XXXI — A dissecção da personalidade psíquica”, v. XXII, p.63-84.

(1938) “Esboço de Psicanálise”, v. XXIII, p.157-229.

(1939) “Moisés e o Monoteísmo”, v. XXIII, p.15-150.

GRESSETH, G.K. (1958) “The system of Aristotle’s Poetics”, in Transactions and Proceedings of the American Philological Association, v. 89. Baltimore, EUA: Johns Hopkins University Press, 312-335.

HEGEL, G.W.F. (1835/1964) Estética - Poesia, v.VII. Lisboa: Guimarães Editores.

\footnotetext{
18 “Onde estava o id, ali estará o ego” (FREUD, 1933/1996, p.84). Para Lacan (1969-70/1992), é também ao analista que se dirige esta fórmula, "lá onde estava o mais-de-gozar, o gozar do outro, que eu, na medida em que profiro o ato analítico, devo advir” (p.50).
} 
KIMMELMAN, G. (1946) “The concept of tragedy in modern criticism”, in The Journal of Aesthetics and Art Criticism, v.4, n.3. Oxford, UK: Blackwell Publishing, 141-160.

KITTO, H.D.F. (1939/1972) Tragédia grega, v.I. Coimbra: Arménio Amado.

LACAN, J. (1997) O seminário livro 7, a ética da psicanálise. Rio de Janeiro, RJ: Jorge Zahar

(1992) O seminário livro 17, o avesso da psicanálise. Rio de Janeiro, RJ: Jorge Zahar.

LEAR, J. (1988) Katharsis. Phronesis, v.33, n.3. Boston, EUA: Brill, p.297326.

LESKY, A. (1957/1976) A tragédia grega. São Paulo: Perspectiva.

LUCAS, D.W. (1962) "Pity, terror, and peripeteia", in The Classical Quarterly, v.12, n.1. Cambridge, UK: Cambridge University Press, p.52-60.

MCMAHON, A.P. (1929) "Seven questions on aristotelian definitions of tragedy and comedy", in Harvard Studies in Classical Philology, v.40. Cambridge: Harvard University Press, p.97-198.

RICOEUR, P. (1969) “Le consciente t l'inconsient”, in Le conflit des interpretations - essais d'herméneutique, p.101-21. Paris: Seuil.

RIGOLOT, F. (2004) "The renaissance fascination with error: mannerism and early modern poetry", in Renaissance Quarterly, v.57, n.4. New York: Renaissance Society of America, 1219-1234.

SZONDI, P.(1964/2004) Ensaio sobre o trágico. Rio de Janeiro: Jorge Zahar.

VERNANT, J.-P.\& VIDAL-NAQUET, V. (1981/2005) “Édipo sem complexo”, in Mito e tragédia na Grécia antiga, p.53-71. São Paulo: Perspectiva.

Hugo Juliano Duarte Matias

hugo_jdm@yahoo.com.br 